\title{
CONNECTING SPACE TO VILLAGE: SERVIR HIMALAYA AT WORK FOR BRINGING EARTH OBSERVATION TO SOCIETAL BENEFITS
}

\author{
B. Bajracharya, MSR Murthy
}

Keywords: SERVIR, Earth observation, Gospatial Information, Satellite image

\begin{abstract}
Earth observation plays an important role in understanding earth as a system by providing repetitive and consistent view throughout the globe for regular assessment and monitoring. There are a number of initiatives working globally to facilitate and promote the earth observation applications. SERVIR is one such global initiative evolved through partnership between USAID and NASA with an overarching goal to improve environmental management and resilience to climate change. SERVIR-Himalaya is being implemented by ICIMOD to provide integrated and innovative geospatial solutions for generation and dissemination of information and knowledge resources on mountain environments in the Hindu Kush Himalaya region. The SERVIR applications are focused on the broad thematic areas which are also subset of the societal benefit areas of Global Earth Observation (GEO), namely - agriculture and food security, ecosystems and sustainable landscapes, and disaster risk management. Some of its applications in Nepal include agriculture drought monitoring; land cover dynamics; biomass estimation at local and national scales; climate change vulnerability to forest ecosystems; multi-scale disaster risk assessment; and forest fire detection and monitoring. Access to these applications and data are facilitated through ICIMOD's Mountain Geoportal and Regional Database System. Regional and national training and workshops, on-the-job training, internships and exchange programs and technical backstopping are key capacity building components to enhance the capacity of national institutions in the regional member countries. These efforts are also seen as receiving feedback on the science applications, identify additional needs, and increase synergy by exploring opportunities for collaboration.
\end{abstract}

\section{INTRODUCTION:}

1.1. Earth Observation in the Global Context Importance of earth observation to understand earth as a system has been increasingly recognized by the global scientific communities and professionals. Earth observation plays a major role in the assessment of our environment by providing repetitive and consistent view throughout the globe. The increasing concerns of climate change impacts in recent decades have emphasized the importance of earth observation applications in the areas such as climate modelling, assessment of snow and glaciers, agriculture monitoring and disaster risk reduction. A number of initiatives have been working globally to facilitate and promote the earth observation applications. The Global Climate Observation System (GCOS) provides for comprehensive observations for research and for detecting and attributing climate change to support the United Nations Framework Convention on Climate Change (UNFCCC) through harmonized national observation systems to avoid both gaps and redundancies in Earth observation programs (Lewis et al 2010). GCOS works towards ensuring free and unrestricted availability of climate and related data for informed decision making. The Committee on Earth Observation Satellites (CEOS), is another principal body for coordinating Earth observation among national civil space programs. It also supports the Group on Earth Observation (GEO), an operational body established in 2005 to provide "a single, comprehensive and sustained system for Earth Observation." GEO, with a permanent secretariat in Geneva, is a voluntary partnership of governments and international organizations that provides a framework for coordinated strategies and investments (GEO 2013). GEO is the body that coordinates and sets up the architecture for the "system of systems" (GEOSS) to ensure complete coverage and compatibility of data. Nepal has been a member nation of GEO since the beginning.

The release of the entire Landsat archive to all users at no cost has been a major contribution to the Geospatial community. Since the Landsat images were made free by the National Aeronautics and Space Administration (NASA) and the United States 
Geological Survey (USGS) in December 2008, over 19 million scenes have been downloaded till August 2014 (USGS 2014). Another encouraging step was the announcement by the White House on 23 September 2014 during the United Nations Heads of State Climate Summit in New York regarding the release the high-resolution $(30 \mathrm{mx} 30 \mathrm{~m})$ images of Shuttle Radar Topography Mission (SRTM) globally. The availability of high resolution Digital Elevation Model (DEM) will help in better analysis of the mountain environments like Nepal.

The visualization using high resolution images, geographic data including 3D terrain in Google Earth has revolutionized the way people use Geographic information. Browsing digital geographic information over the web (geobrowsing) has led to development of innovative applications to explore data geographically, and visualise overlaid information provided by diverse contributors. Integration of geobrowsers such as Google Earth and Google Map through application programming interfaces (APIs) has popularized the use of map for serving all sorts of information. Similarly, introduction of smartphones with map based applications and GPS has brought GIS into fingertips of common people. There is a huge potential for mobile applications in view of $88 \%$ mobile penetration in Nepal (NTA, 2015).

The more open policies on earth observation and wider access and affordability of consumer products enabling use of spatial information has brought in new paradigm in GIS application development and use.

\section{THE SERVIR INITIATIVE}

\subsection{SERVIR-Himalaya: connecting space to village}

SERVIR is a regional visualisation and monitoring system that integrates earth observations such as satellite imagery and forecast models together with in situ data and other knowledge for timely decisionmaking. SERVIR evolved through a 'non-traditional' partnership between USAID (United States Agency for International Development) and NASA to make earth observation data, decision-support tools for interpreting the data, and online mapping capability. SERVIR places a strong emphasis on partnerships to support the access to and availability of earth observations, spatial analysis, and visualisation.

The first SERVIR regional operational facility - for the Latin America and the Caribbean region - was established in 2005 at the Water Center for the Humid
Tropics of Latin America and the Caribbean (CATHALAC). A second SERVIR regional operational facility - for East Africa - was initiated in 2008 at the Regional Center for Mapping of Resources for Development (RCMRD) in Nairobi, Kenya. SERVIR-Himalaya was initiated in late 2010 with ICIMOD, with its focus in the Hindu Kush Himalaya region. SERVIR Himalaya is implemented through ICIMODs regional program Mountain Environment Regional Information System (MENRIS). Very recently, a new hub SERVIR Lower Mekong has been formally launched in November 2014.

The overarching purpose of the SERVIR-Himalaya is to improve environmental decision-making in the Hindu Kush-Himalaya (HKH) region through dissemination and analysis of earth observation information. Stakeholders for this kind of information range from decision-makers at the regional level addressing transboundary issues, to national governments, scientists, students, the general public, donors, and development practitioners.

\section{PRIORITY AREAS AND THEMES}

Driven by the SERVIR's motto 'Connecting Space to Village', SERVIR-Himalaya works as a regional resource centre in the HKH region. The activities of SERVIR-Himalaya are designed from the perspective of Supply (tools, technologies and methods offered by the available Earth observation and Geospatial information systems) and Demand (information gaps, user needs, and creating enabling environments).

Based on the findings of series of needs assessment workshops and also considering ICIMOD's priority areas and GEO societal benefit areas, SERVIR Himalaya has focused on the broader themes of Agriculture and food security, Ecosystems, Cryosphere, Disaster, and Air quality. For each of these themes, assessment of major issues, key stakeholders in the countries, on-going initiatives, gaps and opportunities were carried out. Based on this, a number of Science applications are being developed. These include development of methodologies, customized information systems and web based tools for query and interactive visualization by the target audience. It also works on creating enabling environments through capacity building, creating platforms for access and sharing of data, and wider engagement of users beyond the scientific communities during the process of 
development and dissemination of SERVIR applications.

\section{SERVIR APPLICATIONS IN NEPAL}

SERVIR science applications are designed to address the gaps and needs identified in the national and regional context. Some of the ongoing applications in Nepal are presented here.

\subsection{Satellite based Agriculture Drought Warning System (Nepal)}

Over the last few decades the Himalayan region is experiencing high degree of spatial and temporal climate variability affecting crop production. SERVIR Himalaya is developing satellite based agriculture drought monitoring system to support sub-district level planners and decision makers in Nepal. Over the last year, the crop calendars, crop intensity and area under major crops like rice, wheat and maize are delineated using multi temporal Moderate Resolution Imaging Spectroradiometer (MODIS) satellite data of $250 \mathrm{~m}$ resolution. The crop phenology patterns over the last decade was analysed using fortnightly MODIS $250 \mathrm{~m}$ satellite data. Using this decadal response patterns as a base, fortnightly Normalised Difference Vegetation Index (NDVI) based in season crop growth anomaly maps are generated. Integration of information on seasonal vegetation performance and climate-based drought indicators are used to produce a timely and spatially-detailed drought monitoring information products. Additional datasets (e.g. historical climate and crop production patterns, real-time field based climate and crop data, knowledge of cropping practice, satellite based Moisture based Vegetation Index, Land Surface Temperature (LST), CHIRPS Rainfall data) are being integrated into the system using empirical modeling approaches.

\subsection{Land cover dynamics of Nepal}

Assessment and monitoring of land cover dynamics are essential for the sustainable management of natural resources, environmental protection, biodiversity conservation, and developing sustainable livelihoods, particularly for the rural communities. Under SERVIR, land cover data for 1990, 2000 and 2010 have been derived from Landsat images using object based image analysis. The legend is developed in consultation with national partners using Land Cover Classification System (LCCS) from 위 $\mathrm{FAO} / \mathrm{UNEP}$.
The data are served through an interactive web-based application (Figure 1) which provides user friendly tools for generating statistics to understand the change processes and to support the informed decisions. User are able to access the land cover statistics for the whole country or a selected district. The area of each land cover type can be viewed for all three years together or separately, with the option to make charts on a selected set of classes only. Change map is generated for each class showing the areas of gain or loss while the conversion to or from other classes can be seen on the chart.

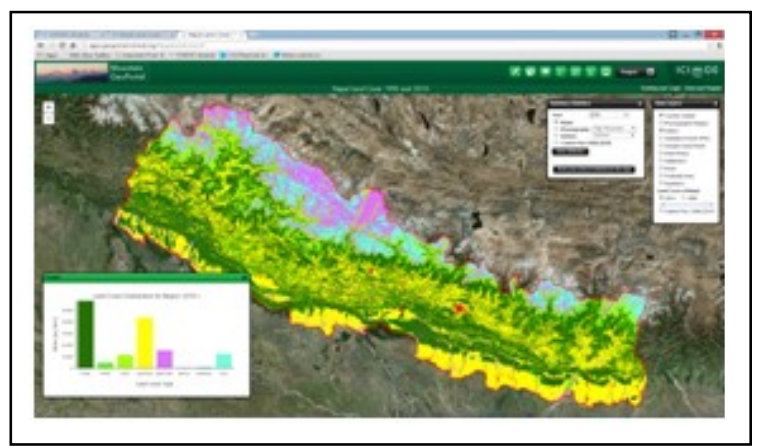

Figure 1. Interactive application for visualization of Nepal land Cover data

\subsection{Biomass estimation using multi-resolution} satellite data at sub-national level

Agriculture, Forest and Other Land Use (AFOLU) system offers a critical basis for creating and safeguarding more climate-resilient communities in Nepal. This has called for reliable baseline assessment of forest biomass and its monitoring strategies at multiple scales to ensure optimal supply - demand resource scenario and also leverage carbon mitigation benefits through mechanisms like Clean Development Mechanism (CDM) and REDD+. The work includes estimation of biomass using multi resolution satellite data and ground information at watershed level. The work has been carried out with community forestry user groups in the three watersheds, one each in Chitwan, Gorkha and Dolakha districts. The methodology has been up-scaled to apply at district level and national levels. A web enabled monitoring system to support mechanisms liked REDD Monitoring, reporting and verification (MRV) is being developed.

\subsection{Multi-scale disaster risk assessment and decision support system for DRR (Nepal) \\ Disaster risk reduction (DRR) efforts needs understanding both as combined effects of multiple disasters and also at individual disaster. However, the requirement of degree and type of understanding}


varies as a function of scale at which DRR management options are operated. A framework consisting of broad information on multiple disasters at national level and detailed information on specific disasters at vulnerable zones would help better preparedness towards disaster risk management. A multilevel hazard and risk analysis system is being developed through wider stakeholder consultation. A decision support system is also being developed by integrating the data and information to aid in decision making for managing flood hazard and associated risk in Nepal.

\subsection{Forest Fire Detection \& Monitoring}

Forest fire is a big concern in many countries including Nepal due to its adverse ecological and economic effects. A need for reliable and time effective information on fire is realized to be important as part of forest fire management. In view of its synoptic and high repetitive coverage, satellite data is found quite useful in fire detection and monitoring, and burnt area assessment on near real time basis. MODIS sensor on board Terra and Aqua satellites of NASA is extensively used for the purpose across the globe. SERVIR Himalaya has developed a forest fire detection and monitoring system for Nepal. The work is being carried out in close collaboration with the Department of Forest. The system carries out automated data acquisition, processing, reporting, and feedback on fire location. It provides location information on active fires present during the satellite's twice-daily overpasses. The system automatically adds important information to these

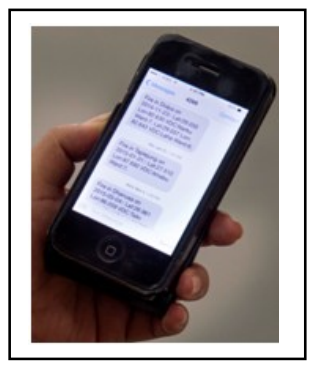
data such as administrative unit (i.e., district, VDC, etc.), protected area identification,

Figure 2. SMS message received from the Forest Fire monitoring application

land cover type, elevation, and slope. The system then sends email notifications and

SMS text about active fires to the subscribers which includes district forest officers, park managers and other relevant stakeholders (Figure 2).

In addition, an interactive mapping application allows visualization of active fire locations on any given day along with district level fire count statistics.

\section{REACHING THE COMMUNITIES}

\subsection{Capacity Building}

Strengthening national and regional capacity to enable the use of earth observation information and geospatial tools for developmental decision-making is the major focus of SERVIR-Himalaya. There is a need to increase awareness and extend SERVIR benefits to ministries and/or national agencies for sustainable use of SERVIR's products and services and foster data sharing and exchange among the multi-sectoral agencies. In this regard, SERVIR has been carrying out various capacity building activities and developing national geospatial portals.

SERVIR-Himalaya conducts customized trainings on its science applications targeted the relevant institutions in the regional countries. The trainings are targeted to participants from different government and non-government agencies, universities and academic institutions. Focused opportunities are provided through on-the-job training to relevant institutions for in-depth skills developed in specific applications. SERVIR Himalaya has been regularly organizing Youth Forum targeting the fresh graduates and young professionals to increase awareness on earth observation application to climate change issues. In collaboration with NASA Develop program, it also provides internships to the students from the region to work on relevant thematic issues.

\subsection{Mountain GeoPortal}

All the science applications and related data are made accessible to the users through ICIMOD's Mountain Geoportal (Figure 3).

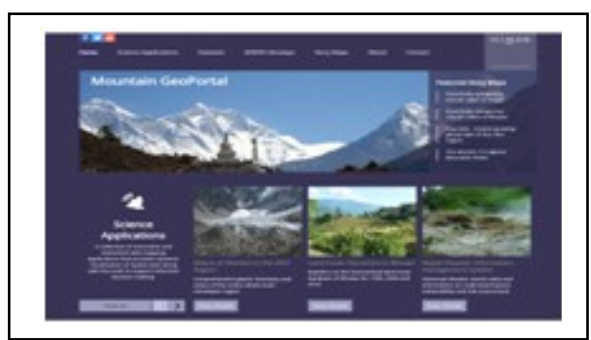

Figure 3. Mountain Geoportal (http://geoportal.icimod.org)

All the science applications are served through the Geoportal with necessary tutorials to access the information and tools. Users can use the web based tools for interactive query and visualization of information in different application areas. Metadata of all the data are also made available through quick and advanced search tools. The data are served through ICIMOD's Regional Database System which allows 
metadata search and downloads. Another feature of the Geoportal is the story maps which integrate geospatial information with related photographs, statistics and text for easy understanding by the users.

SERVIR-Himalaya is consolidating its efforts in Nepal to provide geospatial information services by developing national Geospatial Portals and facilitate the availability and sharing of geo-information. National Geospatial Portals are implemented for coordinated development and delivery of national geospatial services for improved decision-making. These efforts are also seen as a catalytic in complementing national SDI components by building synergies with relevant national programs and initiatives to facilitate data standardization, sharing and exchange. Ultimately it will help create ownership and grow geospatial information services in Nepal.

\section{CONCLUSION}

Over the past decade, ICIMOD, together with national and international partners, has promoted the use of GIS and earth observation applications at multiple scales to support its mission and strategic priorities. These regional priorities are closely interlinked, and improved understanding of the interrelationships between different components is a key challenge. Reliable and timely information on environment and society is critical for such improved understanding of the status, changes and inter-linkages. The emerging initiatives at the global, regional and national fronts and advancements in geospatial technologies has greatly changed the scenario in the user landscape. The easy access to spatial information through mobile devices has mainstreamed the use of spatial information by the common people and has given birth to many applications that are useful in daily life. The new concepts such as GeoDesign to bring geographic analysis into the design process where initial design sketches are instantly vetted for suitability against a myriad of database layers describing a variety of physical and social factors for the spatial extent has opened up enormous opportunities for application developers and decision makers (ESRI 2010). The mobile technologies has also made it possible for materializing the concepts of Citizen Science where the systematic collection and analysis of data and development of technologies are done through public participation.

While Earth observation has proven its usefulness in a wide range of application areas, it is important to consider the context and scale of operation for them to create a real impact. For example, the application on agriculture monitoring is focusing at country level while the forest fire application is implemented at national scales with information dissemination to the local level. The above ground biomass estimation is looking at the watershed level which is now up-scaled at district and national levels. At the watershed level, the primary target group is Community Forestry User Groups while at the national level the line ministry and departments are the primary users.

Another important aspect is to look at the temporal resolution. The forest fire application provides data four times a day while the information on agriculture is carried out fortnightly. Information on forest biomass and land cover are updated over a year to five year period. The temporal resolution is dictated by frequency of satellite data and the variability of the theme.

ICIMOD through its SERVIR Himalaya initiative is striving towards benefiting from these opportunities to make real difference to the people in the HKH. The science applications, trainings and user engagements at various levels are targeted to develop enabling environment in the region where spatial information on all the issues are available to the users and informed decisions are made on the basis of these analyses.

\section{References}

ESRI (2010) Changing Geography by Design, Environment Systems Research Institute

GEO (2013) Report on Progress 2011-2013, Geneva Ministerial Summit, Group on Earth Observation

Lewis, James A., Sarah O. Ladislaw, Denise E. Zheng (2010) Earth Observation for Climate Change - A Report of the CSIS Technology and Public Policy Program, Center for Strategic and International Studies (CSIS).

NTA (2015). MIS Report Poush, 2071 (16 December, 2014 -14 January, 2015), Nepal Telecommunications Authority, Kathmandu. USGS (2014) Landsat Project Statistics - As of August 7, 2014 http://landsat.usgs.gov/Landsat_Project_Statistics.php

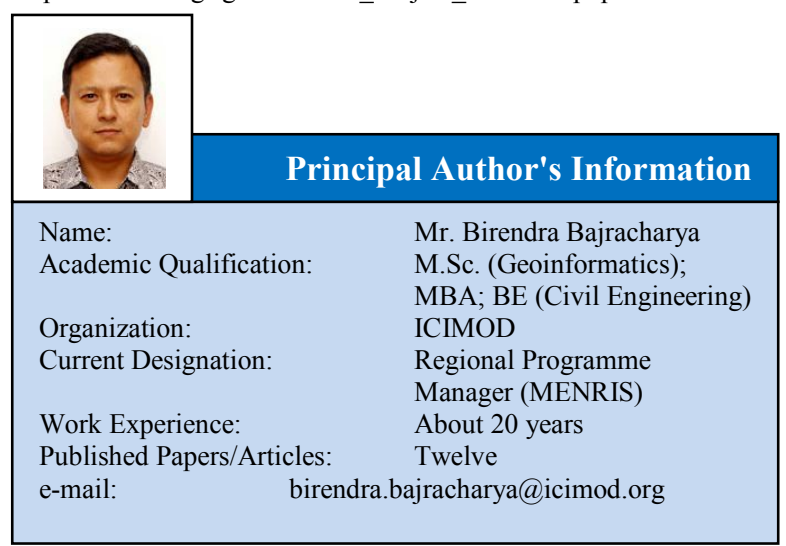

